\title{
Self-Immolation: The Literacy History Between India and Iran
}

\author{
Mohsen Rezaeian,* \\ ${ }^{1}$ Epidemiology and Biostatistics Department, Occupational Environmental Research Center, Rafsanjan Medical School, Rafsanjan University of Medical Sciences, Rafsanjan, IR Iran \\ ${ }^{*}$ Corresponding author: Mohsen Rezaeian, Epidemiology and Biostatistics Department, Occupational Environmental Research Center, Rafsanjan Medical School, Rafsanjan Univer- \\ sity of Medical Sciences, Rafsanjan, IR Iran. Tel: +98-3915234003, Fax: +98-3915225209, E-mail: moeygmr2@yahoo.co.uk \\ Received 2015 January 3; Revised 2015 February 13; Accepted 2015 May 4.
}

Keywords: India, Iran, Self-Immolation

\section{Background}

India as the origin of records of self-burning (1) has witnessed different types of this act (2). According to Hindu mythology, Sati who married Shiva in opposition to her father's wishes was the first woman committed self-immolation (3). Moreover, the self-immolation of a Hindu widow on the funeral pyre of her husband which is called suttee (sati) is an historical forbidden example (3).

It would be important to find out how such stories would travel by means of literacy to other countries. Therefore, the aim of the present article is to highlight how a suttee story has travelled from India to Iran during the 16 th century by the poem and was depicted in a book.

\section{Poem Suz Va Gudaz(Burning and Melting)}

Late Naw'i Khabushani died at the beginning of the 16th century was an Iranian poet who had traveled to India at least twice. One of his masterpieces is the poem Suz va gudaz (burning and melting) which narrates the love story of a Hindu girl who self-immolates on the pyre of her beloved one.

Interestingly, Walters' free manuscript W.649 is an illuminated and illustrated copy of this poem. The codex was written by Ibn Sayyid Murad al-Husayni and illustrated by Muhammad Ali Mashhadi in 1657 (4). There are 8 miniatures in the book; the first one depicts the actual act of self-immolation. The picture below is the full-colored original miniature (Figure 1).

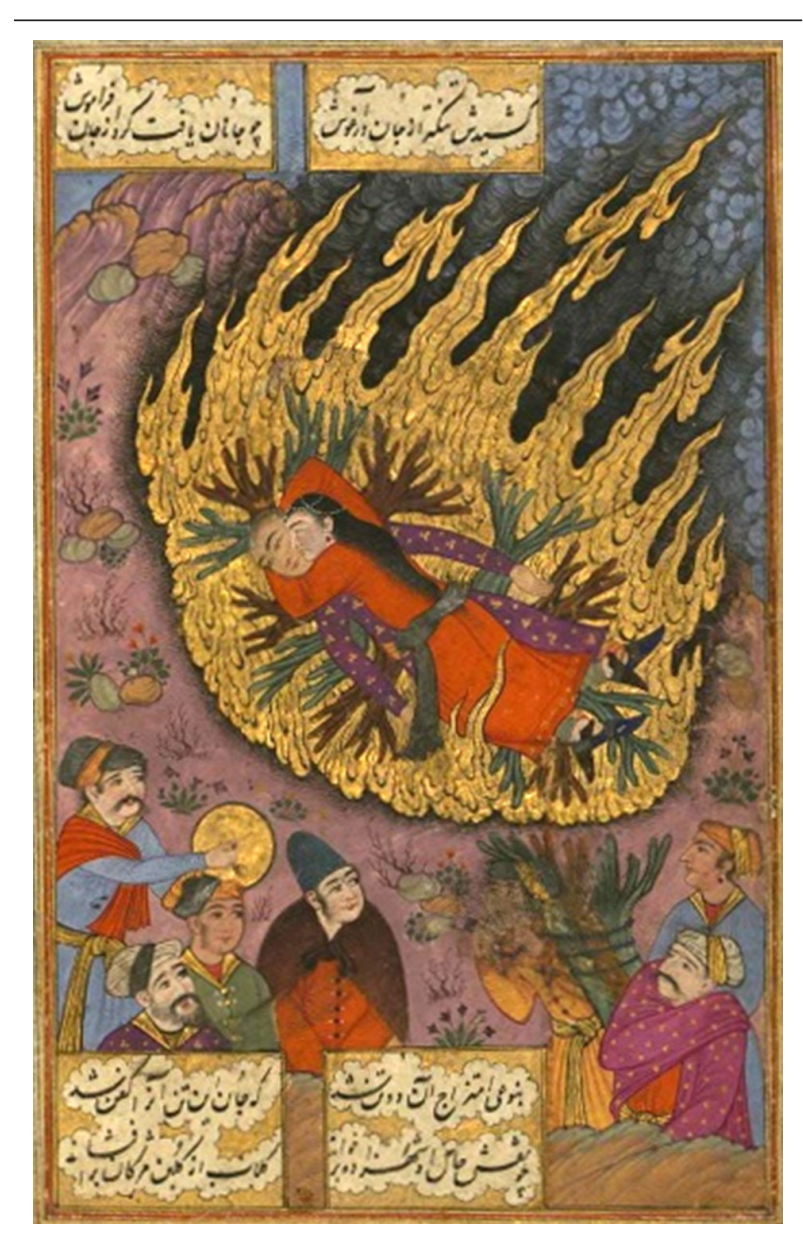

Figure 1. First Miniature of the Book Depicting the Actual Act of Self-Immolation 


\section{Discussion}

Romm et al. in their review entitled: "Self-Immolation: Cause and culture" highlighted that self-immolation was usually applied as a dramatic mythical tool in diverse branches' of arts, including novel, song, movie, and opera (3). Similarly, Naw'i Khabushani in his poem Suz va gudaz has used self-immolation as a dramatic legendary device to narrate a love story (4).

It would be possible to hypothesize that Suz va gudaz poem plus its elegant miniatures might have supported the idea of self-immolation in Iranian poetries and paintings, the extent of which might never be revealed. Recent studies have also suggested that self-immolation usually occurs due to the copycat phenomenon $(5,6)$. As a result, it would also be possible to theorize that this book although to a lesser extent supported the idea of self-immolation among Iranian populations who read the book.

However, the interesting point is that whilst self-immolation in this story depicts a love story, among Iranian contemporary populations it applies as a means of hate and frustration. Therefore, it would be possible to hypothesize that by passing time the meaning of self-immolation and its applications have changed.

It is also worth mentioning that Naw'i Khabushani (4) has not been the first poet who wrote such a self-immolation story in Persian. Amir Hasan Dehlavi who was born in the 12 th century was a famous Indian poet who wrote in Persian. In his "Poem of Love" he narrated a rather similar story of self-immolation (7).

\subsection{Conclusion}

The poem Suz va gudaz plus its elegant miniatures might have supported the idea of self-immolation in Iranian poetries and paintings, the extent of which might never be revealed.

\section{Acknowledgments}

The author would like to thank three anonymous referees for their valuable comments on an earlier draft of this article.

\section{References}

1. Kumar V. Burnt wives--a study of suicides. Burns. 2003;29(1):31-5 [PubMed:12543042]

2. Rezaeian M. Death by burning in Indian women. Burns 2014;40(8):1816-7. doi: 10.1016/j.burns.2014.07.016. [PubMed 25406885]

3. Romm S, Combs H, Klein MB. Self-immolation: cause and culture. J Burn Care Res. 2008;29(6):988-93. doi: 10.1097| BCR.ob013e31818b9ed4. [PubMed:18849845]

4. Khabushani N. Suz va gudaz (Burning and melting). Available from: http://art.thewalters.org/files/pdf/W649.pdf.

5. Zarghami M. Selection of Person of the Year from Public Health Perspective: Promotion of Mass Clusters of Copycat Self-immolation. Iran J Psychiatry Behav Sci. 2012;6(1):1-11. [PubMed: 24644463]

6. Rezaeian M. Epidemiology of self-immolation. Burns. 2013;39(1):1846. [PubMed: 23413444]

7. Dehlavi AH. Hasan of Delhi. Available from: http://encyclopedia2. thefreedictionary.com/Hasan+of+Delhi. 